\section{Correlation between parents' self-efficacy and quality of life of children with cancer aged 8-12 years}

\author{
Imelda Oktaviani, \\ Allenidekania Allenidekania \\ Faculty of Nursing, Universitas \\ Indonesia
}

\begin{abstract}
This study aims to determine the correlation between parents' self-efficacy and the quality of life of children with cancer aged 812 years. Quantitative research using a crosssectional design was carried out on 39 parents and 39 children with cancer. The participants were selected using a consecutive sampling method. The measurement instruments used were the Self-Efficacy for Parenting Task Index (SEPTI), the Pediatric Quality of Life InventoryTM (PedsQLTM) 4.0 Generic Core Scale, and the PedsQL TM 3.0 Cancer Module in the Indonesian version. Data analysis was performed using Pearson's correlation coefficient. The results showed that parents' self-efficacy and the quality of life of children were strongly correlated and that the direction of the correlation was positive $(r=0.680)$. Parents' self-efficacy and quality of life children with cancer were also strongly correlated, and the direction of the correlation was positive $(r=0.715)$. It is recommended that parents and children with cancer ensure the adequate management of cancer treatment.
\end{abstract}

\section{Introduction}

There are around 11,000 annual cases of children with cancer in Indonesia, and around 650 cases of children with cancer in Jakarta alone. ${ }^{1}$ When a child is diagnosed with cancer, adjustments are not only made by the child, but also by their parents. Parents must be prepared to view the changes occurring in their children as the side effects of cancer. Cancer and its treatment has not only physical effects but also social and emotional effects. ${ }^{2}$ They experience fears and worries in relation to their child's life and in relation to whether the treatment will lead to a full recovery. 3 Almost all parents have reported experiencing feelings of distress when watching their child suffer in this way. ${ }^{4}$

This complex response occurs during the initial diagnosis and treatment; it decreased during treatment and worsened when the child's condition deteriorated, and when hospitalization times were extended. 5 Parents needed time to accept their child's condition and control their stress levels. It has been found that stress in the mothers of children with cancer is related to feelings of self-efficacy and fatigue management. ${ }^{6}$ Parents' self-efficacy refers to their estimation of their ability to influence children and their environment to result in positive development. ${ }^{7}$ The initial survey conducted in the Allenidekania \& Nurachmah study in 2015 showed that in 10 mothers who had children with cancer believed that could treat and the self-efficacy average of 34.1 (SD 9.8; minimum/maximum value ranging from 18-46) from a range of total self-efficacy values of $0-100 .{ }^{8}$

Considering the importance of self-efficacy for parents who have children with cancer, this study aims to determine the correlation between parents' self-efficacy and the quality of life of children with cancer. This study is expected to comprise a supportive report that can increase the emphasis placed on self-efficacy for parents and medical practitioners and improving quality of life children with cancer.

\section{Materials and Methods}

\section{Participants}

This study used a quantitative, crosssectional research design and a non-probability sampling method. A period of 3 weeks was allocated for data collection. The participants were 39 parents and 39 children with cancer, selected using consecutive sampling techniques, at the Cancer Care Community and Foundation in Jakarta, Indonesia. The inclusion characteristics of the participants in this study were parents whose children have cancer and children aged 8-12 years undergoing anti-cancer treatments who were all willing to take part in the study. The exclusion characteristics of participants in this study were family members other than fathers and mothers of children with cancer and children with cancer who had experienced a decline in health. The study was declared to have passed the ethical review by the Research Ethics Committee of the Faculty of Nursing Universitas Indonesia (No. 128/UN2.F12. D/HKP.02.04/2019).

\section{Measurement}

The instruments used in this study included a demographic questionnaire, the Self-Efficacy for Parenting Task Index (SEPTI) questionnaire of the parents' reports, the Paediatric Quality of Life Inventory (PedsQLTM) 4.0 Generic Core
Correspondence: Allenidekania Allenidekania, Pediatric Nursing Department, Faculty of Nursing, Universitas Indonesia, Jalan Prof. Dr. Bahder Djohan, Kampus UI Depok, West Java, 16424 Indonesia.

Tel.: +6221.78849120 - Fax: +6221.7864124.

E-mail: alleni@ui.ac.id

Key words: Children with cancer; self-efficacy; quality of life; parents.

Acknowledgments: The writer expresses gratitude to all respondents and their families.

Funding: This study was supported by Hibah PITTA 2019, funded by DRPM Universitas Indonesia (No. NKB-0484/UN2.R3.1/HKP.05 $.00 / 2019)$.

Contributions: IO and AA conceived the idea and plan research, contributed to the design and implementation, verified the analytical method, discussed the result, and reviewed the final manuscript.

Ethical approval: The study was declared to have passed the ethical review by the Research Ethics Committee of the Faculty of Nursing Universitas Indonesia (No. 128/UN2.F12.D/HKP.02.04/ 2019)

Conflict of interest: The authors have no conflict of interest.

This work is licensed under a Creative Commons Attribution NonCommercial 4.0 License (CC BY-NC 4.0).

(C) Copyright: the Author(s), 2020

Licensee PAGEPress, Italy

Pediatric Reports 2020; 12(s1):8703

doi:10.4081/pr.2020.8703

Scale, and the PedsQLTM 3.0 Cancer Module (Indonesian version) of the children's reports. The SEPTI measuring instrument consists of 5 domains developed to assess self-efficacy in parents of primary school-aged children. The SEPTI domains are comprised of discipline, achievement, recreation, nurturance, and health. ${ }^{9}$ The measurement of each item was conducted using a 6-point Likert scale, with answers ranging from very inappropriate to very appropriate. Higher scores are indicative of a higher level of parenting self-efficacy on all subscales after several items are reverse scored.

The PedsQL TM 4.0 Generic Core Scale comprises 4 domains (physical, emotional, social, and school functions) consisting of 23 items. ${ }^{10}$ The items were measured using a 5-point Likert scale ranging from 0 (never having a problem) to 1 (almost never having a problem), 2 (sometimes having a 
problem), 3 (frequently having problems), to 4 (almost always having a problem). ${ }^{10}$ The items were reverse-scored and linearly transformed to a $0-100$ scale $(0=100,1=$ $75,2=50,3=25,4=0$ ) so that the higher the PedsQLTM 4.0 Generic Core Scale score, the better the Health-Related Quality of Life (HRQOL). The PedsQLTM 3.0 Cancer Module instrument is comprised of 8 domains consisting of 27 items. The domains are pain and hurt, nausea, procedural anxiety, treatment anxiety, worry, cognitive problems, perceived physical appearance, and communication. ${ }^{10}$ The format, instructions, measurement scale, and assessment methods were the same as the PedsQLTM 4.0 Generic Core Scale.

\section{Data analysis}

The data analysis was conducted using statistical software. The bivariate analysis of this study used the Pearson correlation test because the numerical data in this study were normally distributed. The bivariate analysis was carried out using the Pearson correlation test to determine whether there was a correlation, correlation strength, and correlation direction between parents' selfefficacy and the quality of life of children with cancer aged 8-12 years.

\section{Results}

Results are resumed in Tables 1-3.

\section{Discussion}

\section{An overview of parents' self-efficacy}

In this study, the average total score of parents' self-efficacy was $172.28( \pm 18.51)$ (Table 1). The subscale with the highest average score was the nurturance subscale. The high score in this subscale was due to parents being required to be more sensitive to the needs and emotions of their children. They must be able to give full attention to their children because they have special needs due to their cancer. The subscale score with the second-highest score was the discipline subscale score, which had a score of 34.82 ( \pm 6.55$)$. The discipline subscale describes parents' ability to apply boundaries to the activities that children should or should not carry out. In this study, the high score in the discipline subscale was due to parents being able to establish rules that were judged appropriate for their child's condition. For example, parents directed their children to use masks when going outside and to limit activities that could cause fatigue.

The third-highest subscale was the health subscale score, which had a score of
$34.72( \pm 4.98)$. The health subscales represent parents' ability to care for and maintain their child's health. The health subscale included the parents' ability to provide appropriate nutrition for their children, obtain preventive and corrective healthcare, detect the signs and symptoms of disease in their children, form habits to maintain cleanliness, encourage their children to get the appropriate rest time, and direct their children's outdoor activities. ${ }^{11}$ The health

subscale score was quite high due to the parents' easy access to health services and the existence of government health insurance programs.

The next subscale score was the recreation subscale score, which had a score of $34.02( \pm 4.26)$. Recreational subscales describe parents' ability to provide entertainment or recreation that can support their children's development. The recreation subscales included regulating their children's

Table 1. Overview of total scores and parents' self-efficiency sub-scale $(n=39)$.

\begin{tabular}{lccc} 
Parents' self-efficacy domain & Mean & SD & CI 95\% \\
Discipline & 34.82 & 6.55 & $32.69-36.94$ \\
Achievement & 33.67 & 4.45 & $32.23-35.10$ \\
\hline Recreation & 34.02 & 4.26 & $32.64-35.40$ \\
Nurturance & 35.05 & 3.78 & $33.83-36.28$ \\
\hline Health & 34.72 & 4.98 & $33.10-36.33$ \\
Total score & 172.28 & 18.51 & $166.28-178.28$ \\
\hline
\end{tabular}

Table 2. Overview of total scores and subscale of PedsQL ${ }^{\text {TM }}$ 4.0 Generic Core Scale and PedsQLTM 3.0 Cancer Module.

\begin{tabular}{lccc} 
Domain & Mean & SD & CI 95\% \\
PedsQLTM 4.0 Generic Core Scale & & & \\
Physical & 61.30 & 27.74 & $52.31-70.29$ \\
Psychosocial & 65.68 & 18.76 & $59.60-71.77$ \\
Emotion & 67.56 & 23.95 & $59.80-75.33$ \\
Social & 75.51 & 22.30 & $68.29-82.74$ \\
School & 53.97 & 20.75 & $47.25-60.70$ \\
Total score & 64.81 & 19.43 & $58.51-71.11$ \\
\hline PedsQLTM 3.0 Cancer Module & & & \\
Pain and Hurt & 64.74 & 26.42 & $56.18-73.31$ \\
Nausea & 54.62 & 27.92 & $45.57-63.67$ \\
Procedural anxiety & 61.33 & 31.27 & $51.19-71.46$ \\
Treatment anxiety & 87.82 & 21.10 & $80.98-94.66$ \\
Worry & 69.02 & 29.43 & $59.48-78.56$ \\
Cognitive problem & 63.72 & 22.64 & $56.38-71.06$ \\
Perceived physical appearance & 75.21 & 24.52 & $67.27-83.16$ \\
Communication & 69.02 & 26.76 & $60.34-77.69$ \\
Total score & 68.18 & 18.50 & $62.19-74.18$ \\
\hline
\end{tabular}

Table 3. Relationship between parents' self-efficacy and quality of life of children with PedsQLTM 4.0 Generic Core Scale and PedsQLTM 3.0 Cancer Module Aged 8-12 years $(\mathbf{n}=39)$.

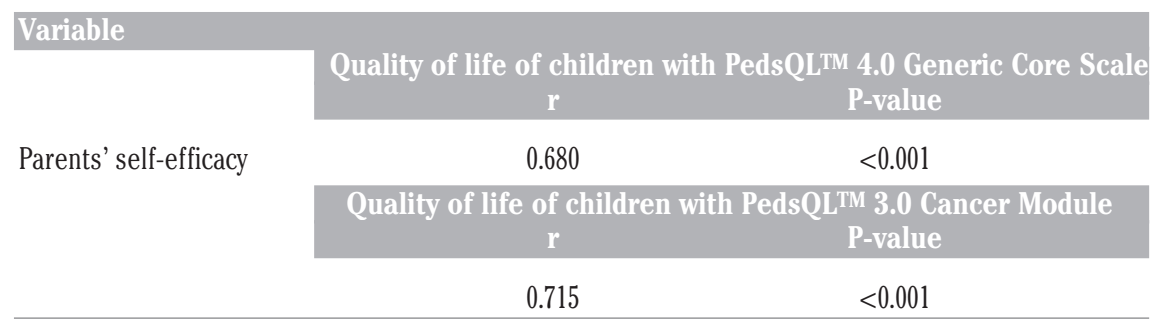


interactions with their peers, providing facilities for recreation according to the age of their children, playing with their children, identifying their children's recreational interests, providing various activities for recreation, and providing space for play. ${ }^{11}$ Children with cancer tended to have lower energy levels and were more prone to fatigue than healthy children. A previous study showed that 65 out of 101 school-age children with cancer did not interact socially. ${ }^{6}$

In this study, the subscale score with the lowest average score was the achievement subscale, which scored $33.67( \pm 4.45)$. Achievement subscales describe parental support for children's achievement in school. Almost all school-age children with cancer are unable to attend school because they feel exhausted and weak, meaning that their learning abilities decrease, and they encounter difficulties when doing their schoolwork. ${ }^{12}$ Children with cancer must undergo routine treatment in the hospital. Medical treatment protocols in pediatric oncology are often given according to a schedule that requires the child to be at the hospital for a couple of days, return home for 2 or 3 weeks, then return to the hospital, and so forth. ${ }^{13}$

\section{An overview of quality of life of children with generic core scale (PedsQLTM 4.0 Generic Core Scale)}

The results of the analysis conducted in this study were based on the results of the study conducted by Varni, Burwinkle, Katz, Meeske, and Dickinson in 2002. The average total score and subscale of the PedsQLTM 4.0 Generic Core Scale reported by Varni et al. is the basis for categorizing the good or bad results of this study. The total score and the subscale of the PedsQLTM 4.0 Generic Core Scale are categorized as being good if the value is above the average value of the total score and subscale of PedsQLTM 4.0 Generic Core Scale reported by Varni et al., and vice versa. In this study, the average total score of the PedsQLTM 4.0 Generic Core Scale for children with cancer was $64.81( \pm 19.43)$ (Table 2 ). These results are lower than the results of the study by Varni et al., who reported a result of $72.20( \pm 16.38) .10$ The low value of the total score and subscale of the study was due to the fact that the majority of children with cancer in the study were undergoing an intensive chemotherapy phase, had different healthcare facilities, and had different cultural background.

In this study, the psychosocial subscale scored higher than the average physical subscale. These results are similar to other studies. ${ }^{10,14-17}$ The results of the emotional subscales are below the results of other studies. ${ }^{10,14-17}$ Emotional problems in children with cancer are a side effect of secondary reactions to their chemotherapy treatment. ${ }^{18,19}$ In this study, the physical subscale received a score similar to other studies. $14,20,21$ There were significant differences in the physical health of children with cancer undergoing intensive and non-intensive treatment phases. ${ }^{14}$ This is because intensive-phase chemotherapy treatment is aggressive in killing cancer cells.

In this study, the subscale with the lowest average score was the school subscale, which had a score of $53.97( \pm 20.75)$. This score is similar to other studies. ${ }^{10,14,17,21} \mathrm{~A}$ study reported that children with cancer experienced some impact on academic performance and had to input extra effort in order to continue their education. ${ }^{22}$ Schoolage children with cancer have to undergo regular treatment, meaning that they do not attend school and are limited in their developmental stages.

In this study, the average subscale score of the social subscale had the highest average value compared to other subscales. The length of the diagnosis duration can be a time of adaptation for children with cancer, and they had no difficulty in getting along with their friends and other people. This is similar to other studies, where it was also reported that social subscale had the highest average value. $10,14,16,17,20,21$ It was found that school-age children wanted to build their skills and participate in meaningful and socially beneficial work. ${ }^{23}$

\section{An overview of quality of life of children with cancer module (PedsQL TM 3.0 Cancer Module)}

The results of the analysis of this study was based on the results of the study by Varni et al. The average total score and subscale of the PedsQLTM 3.0 Cancer Module reported by Varni et al. form the basis for categorizing the good and bad results of this study. The average total score of the Cancer Module PedsQLTM 3.0 in this study was $68.18( \pm 18.50)$. This result is much lower when compared to the results of Varni et al. In this study, the average score of the worry subscale and the pain/ache subscale was below the study results of Varni et al. 10 Meanwhile, the nausea subscale in this study received the lowest average score. The widespread cell/tissue damage resulted in specific side effects in certain locations, and children undergoing chemotherapy may experience more general side effects, including fatigue, anorexia, changes in taste, nausea, and vomiting, and pain. ${ }^{24}$

The score for the procedural anxiety subscale was low, at $61.33( \pm 31.27)$, in line with proxy reports by Varni et al., where the score was $60.26( \pm 32.86) .10$ The result of this study was different from that of Baggott et al., where a score of $67.5( \pm 28.3)$ was reported in children aged $<13$ years. ${ }^{20}$ The difference in scores is due to the existence of supportive care interventions (e.g., administration of anesthesia during invasive procedures, more routine use of antiemetics). ${ }^{20}$ This is in accordance with the study by Novrianda, Yetti, and Agustini, where it was stated that supportive action was needed to reduce anxiety in children in relation to painful treatment. ${ }^{17}$ The low score on the procedural anxiety subscale of this study was due to the fact that in Indonesia, the application of atraumatic care-based nursing care to children undergoing cancer treatment is still suboptimal.

The subscales of cognition and communication problems also had a low value. In this study, the subscale of cognition problems obtained an average score of 63.72 $( \pm 22.64)$. Meanwhile, the communication problem subscale obtained an average score of $69.02( \pm 26.76)$. Children with cancer often complained about the cognitive problems they experienced, including decreased short-term memory, difficulty focusing, lack of speed in counting, and difficulty concentrating. ${ }^{8}$ Children and guardians reported that in the intensive phase, the procedural anxiety and communication subscale scored lower. ${ }^{14}$ Thus, in this study, a low score on the cognition and communication problems subscales was due to the impact of cancer itself, the side effects of treatment, and the treatment phase being undertaken by the children.

The average score of the management/treatment anxiety subscale in this study has the highest average value. This was similar to other studies. ${ }^{10,14}$ However, this result was different from the study conducted by Novrianda, Yetti, and Agustini, where a high score was obtained regarding perceived physical appearance. ${ }^{17}$ Differences in scores that occur can be caused by multiple factors, including the quality of health services and care, the support of one's parents/guardians, and the status of the child's illness. The low scores on the procedural anxiety subscale and the management/treatment subscale can be attributed to the adjustment of children to the environment and treatment procedures (e.g., medical examinations, regular drug consumption, chemotherapy), thus making them more likely to fear things and actions that are unknown. This is supported by existing research, where it was found that complicated treatment protocols, including chemotherapy, intra-spinal drug injections, radiotherapy, and surgery, caused tension in children and parents. 25 


\section{Relationship between parents' self-efficacy and quality of life of children with generic core scale (PedsQL TM 4.0 Generic Core Scale)}

In the bivariate analysis, there was a significant relationship between parents' selfefficacy and the quality of life of children with cancer (PedsQLTM 4.0 Generic Core Scale) $(p<0.05)$. A value of $r=0.680$ was obtained, which means parents' self-efficacy and the quality of life of children with cancer (PedsQL TM 4.0 Generic Core Scale) having the strength of a strong relationship and the positive direction of a relationship (Table 3 ). Thus, the higher parents' self-efficacy, the higher the quality of life of children with generic cancer. Invasive treatment procedures, stress from the many procedures needed for children with cancer, and parents' selfefficacy in treating children with cancer play an important role in determining the reactions of children to treatment. ${ }^{26}$ Another study reported the correlation between parenting stress and parenting self-efficacy showed that as self-efficacy increased, levels of parenting stress decreased. ${ }^{27}$

Increasing parents' self-efficacy and decreasing stress were necessary to change children's behavior. Another study reported that the quality of life of children with generic cancer can also be improved by fatigue management, with mothers' selfefficacy evidenced by an increase in the average score of quality of life of children with generic cancer before the intervention, at $67.70( \pm 1.13)$, and after the intervention, at $75.90( \pm 1.23) .{ }^{8}$ The study reported that if children did not receive the intervention model of fatigue management, their quality of life would decrease, multidimensional fatigue would increase, and their functional status would decrease. ${ }^{8}$ This proves that there is a need for high levels of self-efficacy in parents in order to improve the quality of life of children with generic cancer.

\section{Relationship between parents' self-efficacy and quality of life of children with cancer module (PedsQLTM 3.0 Cancer Module)}

In the bivariate analysis, there was a significant relationship between parents' self-efficacy and the quality of life of children with cancer (PedsQLTM 3.0 Cancer Module) $(\mathrm{P}<0.05)$. A value of $\mathrm{r}=0.715$ was obtained, which means parents' self-efficacy and the quality of life of children with cancer (PedsQLTM 3.0 Cancer Module) having the strength of a strong relationship and the positive direction of a relationship (Table 3). This showed that the higher parents' self-efficacy, the higher the quality of life for children with module cancer.
According to a study by Allenidekania in 2015 , differences in life-quality scores in children with cancer using the PedsQLTM 3.0 Cancer Module in Indonesia were influenced by children factors, the type of cancer, parents, familial factors, support from medical professionals, and the availability of care facilities. ${ }^{8}$

High levels of tension in parents were associated with emotions, sleep disturbances, changes in work status, and time and financial demands. ${ }^{28}$ The self-efficacy of parents was inversely correlated with tension, anger, and fatigue, and positively correlated with strength. ${ }^{28}$ Parents of children with serious illnesses are beset by more negative moods and experience less enthusiasm than adults in normative samples, and levels of fatigue are similar to those reported by psychiatric outpatients. ${ }^{28}$ Parents' self-efficacy when looking after their children has proven to be an important barrier against children's stress. It comprised a strategy to support parents and was recognized as an effective way of improving children's health, well-being, and development. ${ }^{27}$ The higher parents' self-efficacy is in relation to their ability to keep their children calm during procedures can make children have fewer difficulties, meaning that their ability to cooperate during procedures is raised. 26

\section{Conclusions}

This study showed that there is a relationship between parents' self-efficacy and the quality of life of children with cancer (both generic and module cancer). This study shows that the level of parents' selfefficacy and the quality of life of children with cancer need to be improved. When providing nursing care, nurses need to focus on the quality of care given, provide emotional support, and optimize school functions of children suffering from cancer who are undergoing treatment in hospitals or halfway houses to improve parents' selfefficacy and children's educational abilities.

\section{References}

1. The Ministry of Health Republic of Indonesia. Buletin situasi penyakit kanker [Internet]. Pusat Data dan Informasi Kemenkes RI (The Ministry of Health Republic of Indonesia); 2015. Available from: http://www.depkes.go. id/download.php?file

2. Hilda H, Lubis B, Hakimi H, Siregar OR. Quality of life in children with cancer and their normal siblings. Paediatr Indones 2015;55:243-7.
3. Ben-Zur H, Khoury SM. Ethnicity moderates the effects of resources on adjustment of Jewish and Arab mothers of children diagnosed with cancer. J Psychosoc Oncol 2017;35:688-705.

4. Enskär K, Hamrin E, Carlsson M, Essen von L. Swedish mothers and fathers of children with cancer: Perceptions of well-being, social life, and quality care. J Psychosoc Oncol 2011;29:51-66.

5. Naulia RP. Analisis faktor-faktor yang berhubungan dengan stres pada anak pengidap kanker dan ibunya. [Unpublished Thesis]. Depok: Universitas Indonesia; 2016.

6. Allenidekania A, Nurachmah E. The impact of mother education program to stress, knowledge, and self-efficacy related to fatigue management among Indonesian mothers of children with cancer. Off J Multinatl Assoc Support Care Cancer 2015;23:4-18.

7. Dumka LE, Gonzales NA, Wheeler LA, Millsap RE. Parenting self-efficacy and parenting practices over time in Mexican American families. J Fam Psychol 2010;24:522-31.

8. Allenidekania A, Nurachmah E. Efektifitas model manajemen kelelahan (fatigue) berfokus pada efikasi diri ibu yang memiliki anak dengan kanker. [Unpublished Thesis]. Depok: Universitas Indonesia; 2015.

9. Coleman PK, Karraker KH. Parenting self-efficacy among mothers of school age children: Conceptualization, measurement, and correlates. Fam Relat 2000;49:13-24.

10. Varni JW, Burwinkle TM, Katz ER, et al. The PedsQL in pediatric cancer: Reliability and validity of the pediatric quality of life inventory generic core scale, multidimensional fatigue scale, and cancer module. Am Cancer Soc 2002;94:2090-106.

11. Coleman PK, Karraker KH. Self-efficacy and parenting quality finding and future applications. Dev Rev 1998;18: 47-85.

12. Nurhidayah I, Hendrawati S, Mediani HS, Adistie F. Kualitas hidup anak dengan kanker. Jurnal Keperawatan Padjajaran 2016;4:45-59.

13. Cernvall M, Carlbring P, Ljungman G, Essen L V. Guided self-help as intervention for traumatic stress in parents of children with cancer: Conceptualization, intervention strategies, and a case study. J Psychosoc Oncol 2013;31:13-29.

14. Sitaresmi MN, Mostert S, Gundy CM, et al. Health-related quality of life assessment in Indonesian childhood acute lymphoblastic leukemia. Health Qual Life Outcomes 2008;6:1-8. 
15. Sung L, Klassen R, Pritchard S, et al. Identification of pediatric cancer patients with poor quality of life. Br J Cancer 2009;100:82-8.

16. Sabbah I, Sabbah H, Sabbah S, et al. Measurement properties of the Arabic Lebanon version of the pediatric quality of life inventory 4.0 generic core scales for young child (5-7 years), and child aged 8-12 years: Quality of life in urban and rural children in Lebanon. Creat Educ 2012;3:959-70.

17. Novrianda D, Yetti K, Agustini N. Faktor-faktor berhubungan dengan kualitas hidup anak leukemia limfositik akut yang menjalani kemoterapi. Jurnal Keperawatan Padjajaran 2016;4:1-10.

18. Scarpelli AC, Paiva SM, Pordeus IA, et al. Measurement properties of the Brazilian version of the pediatric quality of life inventory (PedsQLTM) cancer module scale. Health Qual Life Outcomes 2008;6:1-11.

19. Castillo-Martinez D, Juarez-Villegas LE, Palomo-Colli MA, et al. Quality of life in children with acute lymphoblastic leukemia during induction therapy with PedsQL Cancer Module. Bol Med Hosp Infant Mex 2009;12-8.

20. Baggott CR, Dodd M, Kennedy C, et al. An evaluation of the factors that affect the health-related quality of life of children following myelosuppressive chemotherapy. Support Care Cancer 2011;19:353-61.

21. Arslan FT, Basbakkal Z, Kantar M. Quality of life and chemotherapy-related symptoms of Turkish cancer children undergoing chemotherapy. Asian Pacific J Cancer Prev 2013;14:1761-8.

22. William Li H, Lopez V, Chung OJ, et al. The impact of cancer on the physical, psychological, and social well-being of childhood cancer survivors. Eur J Oncol Nurs 2013;17:214-9.

23. Hockenberry MJ, Wilson D. Wong's nursing care of infants and children. 10th ed. Canada: Elsevier Inc; 2015.

24. Selwood K. Side effects of chemotherapy. In: Gibson F, Soanes L (eds.) Cancer in children and young people: Acute nursing care. Chichester, England: John Wiley Sons Ltd.; 2008: p.35-71.

25. Tsai MH, Hsu JF, Chou WJ, et al. Psychosocial and emotional adjustment for children with pediatric cancer and their primary caregivers and the impact on their health-related quality of life during the first 6 months. Qual Life Res 2013;22:625-34.

26. Peterson AM, Harper FWK, Albrecht TL, et al. Parent caregiver self-efficacy and child reactions to pediatric cancer treatment procedures. J Pediatr Oncol Nurs 2014;31:18-27.

27. Bloomfield L, Kendall S. Parenting self-efficacy, parenting stress, and child behaviour before and after a parenting programme. Prim Health Care Res Dev 2012;13:364-72.

28. Byrne MW, Evan E, Goshin LS, et al. Parent self-efficacy for managing pain in seriously ill children and adolescents nearing end of life. Palliat Support Care 2011;9:137-47. 